\title{
Reactivation and Reconsolidation of Long-Term Memory in the Crab Chasmagnathus: Protein Synthesis Requirement and Mediation by NMDA-Type Glutamatergic Receptors
}

\author{
María Eugenia Pedreira, Luis María Pérez-Cuesta, and Héctor Maldonado \\ Laboratorio de Neurobiología de la Memoria, Departamento de Fisiología y Biología Molecular, Pabellón Il, Facultad de \\ Ciencias Exactas y Naturales (C1428EHA), Universidad de Buenos Aires, Argentina
}

Experiments with invertebrates support the view that intracellular events subserving the consolidation phase of memory are preserved across evolution. Here, we investigate whether such evolutionary persistence extends to reconsolidation mechanisms, which have recently received special attention in vertebrate studies. For this purpose, the memory model of the crab Chasmagnathus is used. A visual danger stimulus (VDS) elicits crab escaping, which declines after a few stimulus presentations. The long-lasting retention of this decrement, called context-signal memory (CSM), is mediated by an association between contextual cues of the training site and the VDS. The present results show amnesia for CSM in crabs re-exposed at 24 $\mathrm{hr}$ (day 2) for $5 \mathrm{~min}$ to the learning context, $24 \mathrm{hr}$ after training, and injected with one of two amnesic agents, then tested $24 \mathrm{hr}$ later. Agents and timing were either $15 \mu \mathrm{g}$ of cycloheximide given between $1 \mathrm{hr}$ before and $4 \mathrm{hr}$ after re-exposure or $1 \mu \mathrm{g} / \mathrm{gm}$ (+)-5-methyl-10,11-dihydro-5H-dibenzo[a, d]cyclohepten-5,10imine given between $1 \mathrm{hr}$ before and $2 \mathrm{hr}$ after re-exposure. The amnesic effects are specific to behavior that occurs a long time after reactivation but not a short time after. No CSM deficit is produced by such agents when crabs are exposed to a context different from that of training. Findings are consistent with those reported for vertebrates, with both showing that reactivation induces a recapitulation of the postacquisition cascade of intracellular events. The agreement between results from such phylogenetically disparate animals suggests that evolution may have adopted a given molecular cascade as the preferred means of encoding experiences in the nervous system.

Key words: reactivation; reconsolidation; invertebrate; context reminder; cycloheximide; MK-801; memory; crab; crustacea
Evidence from invertebrate species such as Aplysia (Abel and Kandel, 1998; Alberini, 1999), Drosophila (Tully et al., 1994; Tully, 1998), honeybee (Müller, 2000; Menzel, 2001), and the crab Chasmagnathus (for review, see Maldonado, 2002) lends support to the view that both the memory consolidation phase after acquisition and the cascade of intracellular events subserving consolidation are preserved across evolution. Since the early work of Misanin et al. (1968) more than three decades ago, there has been renewed interest in another phase of memory, namely the reminder-reactivated memory. An increasing number of studies with vertebrates show that reactivated old memories become labile and sensitive to amnesic treatment. Such vulnerability decreases over time, indicating that reactivation is followed by a temporally graded reconsolidation (Nader et al., 2000; Sara, 2000). In addition, it has been proposed that reconsolidation uses many of the same cellular and molecular mechanisms as consolidation (Nadel and Land, 2000). Although previous studies have also demonstrated the phenomenon of reconsolidation in an invertebrate, the garden slug Lymax (Sekiguchi et al., 1997), no one has addressed the mechanisms mediating reconsolidation in a simple system. Thus, the purpose of the present article is to

\footnotetext{
Received March 20, 2002; revised July 3, 2002; accepted July 3, 2002.

This work was supported by the Agencia Nacional Científica y Tecnológica (PICT-1-06602). We thank Dr. Alejandro Delorenzi, Dr. Arturo Romano, and Dr. Daniel Tomsic for reading this manuscript and for helpful criticism and Angel Vidal for technical assistance.

Correspondence should be addressed to Dr. Héctor Maldonado, Laboratorio de Neurobiología de la Memoria, Departamento de Fisiología y Biología Molecular, Pabellón II, Facultad de Ciencias Exactas y Naturales (C1428EHA), Universidad de Buenos Aires, Buenos Aires, Argentina.

Copyright (C) 2002 Society for Neuroscience $\quad 0270-6474 / 02 / 228305-07 \$ 15.00 / 0$
}

investigate the memory reconsolidation phase and the mechanisms subserving it by using the memory model of the crab Chasmagnathus, extensively studied at the behavioral and mechanistic levels (Maldonado, 2002).

The associative learning paradigm of the crab is based on its escape response, elicited by the presentation of a visual danger stimulus (VDS) (an opaque rectangle passing overhead). With the iterative presentation of the VDS, the crab's response declines and a strong freezing is built up (Pereyra et al., 1999, 2000). The response decrement lasts for at least 5 d (Lozada et al., 1990; Pedreira et al., 1995). This memory is mediated by an association between the environmental features of the training site (the context) and the features of the screen moving overhead (the signal) (Tomsic et al., 1998), so that it is called context-signal memory (CSM). Studies about mechanisms underlying consolidation have shown that CSM consolidation is cycloheximide (CHX)-sensitive (Pedreira et al., 1995, 1996; Hermitte et al., 1999); is positively modulated by angiotensins (Delorenzi et al., 1996, 2000); is selectively regulated by a muscarinic cholinergic mechanism (Berón de Astrada and Maldonado, 1999); and is mediated by the cAMP signal pathway (Romano et al., 1996a,b; Locatelli et al., 2000, 2002), by nuclear factor- $\kappa \mathrm{B}$ transcription factor (Freudenthal et al., 1998; Freudenthal and Romano, 2000; Merlo et al., 2002), and by NMDA-like glutamatergic receptors (Troncoso and Maldonado, 2002).

Specifically, experiments here are aimed at determining whether the CSM of the crab could be reactivated by short re-exposure to the context after a period of being impervious to amnesic agents. If so, the next step is to characterize the retrieval properties and to ascertain whether reconsolidation requires the 
same cellular machinery as consolidation, starting with the protein synthesis requirement and the mediation of NMDA-type glutamatergic receptors.

\section{MATERIALS AND METHODS}

\section{Animals}

Animals were adult male Chasmagnathus crabs $2.7-3.0 \mathrm{~cm}$ across the carapace, weighing $\sim 17.0 \mathrm{gm}$, collected from water $<1 \mathrm{~m}$ deep in the rías (narrow coastal inlets) of San Clemente del Tuyú, Argentina, and transported to the laboratory, where they were lodged in plastic tanks $(35 \times 48 \times 27 \mathrm{~cm})$ filled to $2 \mathrm{~cm}$ depth with diluted marine water to a density of 20 crabs per tank. Water used in tanks and other containers during the experiments was prepared using hw-Marinex (Winex, Hamburg, Germany), salinity $10-14 \%$, at a $\mathrm{pH}$ of $7.4-7.6$, and maintained within a range of $22-24^{\circ} \mathrm{C}$. The holding and experimental rooms were maintained on a $12 \mathrm{hr}$ light/dark cycle (lights on 7:00 A.M. to 7:00 P.M.). Animals were fed rabbit pellets (Nutrientes S.A., Buenos Aires, Argentina) every $3 \mathrm{~d}$, and the water was changed after feeding. Experiments were performed within the first week after the animal's arrival, from January to August, and between 8:00 A.M. and 6:00 P.M. Each crab was used in only one experiment. Experimental procedures are in compliance with the Guide for the Care and Use of Laboratory Animals published by the National Institutes of Health.

\section{Apparatus}

The apparatus has been described in detail previously (Maldonado, 2002). Briefly, the experimental unit was the actometer: a bowl-shaped opaque container with a steep concave wall $12 \mathrm{~cm}$ high $(23 \mathrm{~cm}$ top diameter and $9 \mathrm{~cm}$ floor diameter) covered to a depth of $0.5 \mathrm{~cm}$ with marine water. The crab was lodged in the container, which was suspended by three strings from an upper wooden framework $(23 \times 23 \times 30$ $\mathrm{cm}$ ) and illuminated with a $10 \mathrm{~W}$ lamp placed $30 \mathrm{~cm}$ above the animal. A motor-operated screen (an opaque rectangular strip of $25.0 \times 7.5 \mathrm{~cm}$ ) was moved horizontally over the animal's head, cyclically from left to right and vice versa. A trial lasted nearly 9 sec and included two successive cycles of movement. Screen displacements provoked a running response of the crab and subsequent container vibrations. A stylus was cemented centrally to the bottom of the container and connected to a piezoelectric transducer. Container vibrations induced electrical signals proportional to the amplitude and frequency of the vibrations through the transducer. These signals were amplified, integrated during each 9 sec trial, and translated into arbitrary numerical units ranging from 0 to 5000 before being processed by computer. The activity of every crab was recorded during each entire trial time. The experimental room had 40 actometers, separated from each other by partitions. A computer was used to program trial sequences, trial duration, and intertrial intervals and to monitor experimental events.

\section{Experimental procedure and design}

Each crab was moved from the holding room to one actometer in the experimental room. Each experiment lasted $3 \mathrm{~d}$ and included three phases: training session, treatment session, and test session, each corresponding to $1 \mathrm{~d}$. Two pairs of groups, $30-40 \mathrm{crabs}$ each, were formed in each experiment, called pair $a$ and pair $b$, whose protocols differed in the treatment session (day 2).

Day 1: training session. Either pair $a$ or pair $b$ included one untrained group (U), which was kept in the actometers during the entire training session $(\sim 50 \mathrm{~min})$ but without being trained (i.e., without being presented with the VDS), and one trained group (T), which, after 5 min in the actometer without a VDS (adaptation time), received 15 trials with a VDS separated by an intertrial interval of $3 \mathrm{~min}$. The actometer used during the training session is referred to as the standard context. Immediately after the training session, crabs were moved from the standard context to be housed individually in the resting containers (i.e., plastic boxes covered to a depth of $0.5 \mathrm{~cm}$ with water and kept inside dimly lit drawers) for $24 \mathrm{hr}$.

Day 2: treatment session. The core of this phase was the re-exposure of the crab for $5 \mathrm{~min}$ to the standard context without VDS presentation or to a context unlike that of the training session, referred to as the different context. It consisted of a cylinder $15 \mathrm{~cm}$ high and $15 \mathrm{~cm}$ in diameter, whose wall consisted of vertical black and white bands, illuminated like the actometers. An injection with physiological or drug solution was given at diverse times relative to the 5 min context exposure, during the same day 2. Pair $a$ and pair $b$ differed from each other in one item of the treatment: either the drug injected or the time interval between injection and context exposure.

Day 3: test session. After $24 \mathrm{hr}$ in the resting containers, all crabs were again placed in the standard context for $5 \mathrm{~min}$, but this time followed by the test trial (i.e., the VDS presentation).

Before animals were placed in the actometers to start an experiment, they underwent a selection test: each crab was turned on its back, and only animals that immediately returned to their normal position were used. The rationale behind this selection is that crabs with a slow righting reaction show a low responsiveness to a large diversity of stimuli and, at a later time, they usually present unhealthy symptoms. No more than $5 \%$ of tested crabs were eliminated.

\section{Drugs and injection procedure}

Crustacean saline solution (SAL) (Hoeger and Florey, 1989) was used as the vehicle. Fifty microliters of saline or drug solution was given through the right side of the dorsal cephalothoracic-abdominal membrane by means of a syringe fitted with a sleeve to control the depth of penetration to $4 \mathrm{~mm}$, thus ensuring that the injected solution was released in the pericardial sac.

CHX and the NMDA receptor antagonist (+)-5-methyl-10,11dihydro-5H-dibenzo $[a, d]$ cyclohepten-5,10-imine (MK-801) were purchased from Sigma (St. Louis, MO).

\section{Data analysis}

CSM retention was assessed by focusing data analysis on test trial scores [i.e., by estimating the difference between the response level of the trained group $(\mathrm{T})$ and that of the respective untrained group (U) of each pair]. A trained group is said to show memory retention when its mean response level at test trial is statistically lower than that of the respective untrained group. Rescorla (1988) convincingly argued in favor of using this sort of analysis instead of a paired training-testing comparison, stressing the need to clearly distinguish between time of input (training session) and time of assessment (testing session). This view is amply justified in the present case, because it has been demonstrated that CSM retention in the crab is independent of the escape response level at training (Tomsic et al., 1991), a result consistent with similar findings in other animals (Applewhite et al., 1969; Peeke and Veno, 1976).

In previous experiments at our laboratory, a significant difference $(t$ test; $p<0.05$ ) between the $\mathrm{T}$ and $\mathrm{U}$ groups was invariably disclosed at the test trial $(\mathrm{T}<\mathrm{U}), 24 \mathrm{hr}$ after training, provided that each group consisted of $\geq 30$ crabs each and that they were given $\geq 15$ training trials with $3 \mathrm{~min}$ of intertrial interval. Such a significant difference was also found when crabs were injected with saline before or after training. Accordingly, prediction is feasible for a significant difference $(\mathrm{T}<\mathrm{U})$ at test trial, and therefore, results here are analyzed using a priori planned comparisons (Rosenthal and Rosnow, 1985; Howell, 1987). For each experiment, which includes two U-T pairs of groups (pair $a$ and pair $b$ ), three comparisons were performed: the first one between the two untrained groups, a second for the $\mathrm{U}$ group versus the T group of pair $a$, and a third for the $\mathrm{U}$ group versus the T group of pair $b$. Each set of planned comparisons was performed according to a significant main effect in one-way ANOVA $(p<0.05)$. All response scores are represented as mean \pm SEM. We analyzed the data using Statistica '99 edition (Windows 6.1 software package; StatSoft Inc., Tulsa, OK).

\section{RESULTS}

\section{Effect of $\mathrm{CHX}$ administered at diverse times relative to re-exposure to the original learning context}

It was demonstrated previously that $10-15 \mu \mathrm{g}$ per crab of $\mathrm{CHX}$, which inhibits $\sim 90 \%$ of protein synthesis in Chasmagnathus for $>2 \mathrm{hr}$, impairs newly acquired CSM when given from $1 \mathrm{hr}$ before or up to $\sim 6 \mathrm{hr}$ after training (Pedreira et al., 1995). Here, we test whether the consolidated memory could be reactivated by a reminder and converted to a labile state. For this purpose, a similar dose of CHX $(15 \mu \mathrm{g})$ was given at varying times relative to the crab's exposure to a standard or to a different context.

In the following five experiments, presented in Figure $1 A-E$ (left panels), crabs were injected with either SAL or $\mathrm{CHX}$ at diverse times relative to $5 \mathrm{~min}$ of context exposure during day 2 . Each experiment includes a U-T pair $a$ (SAL-injected) and a pair 


\section{Day 1 Day 2 Day 3}
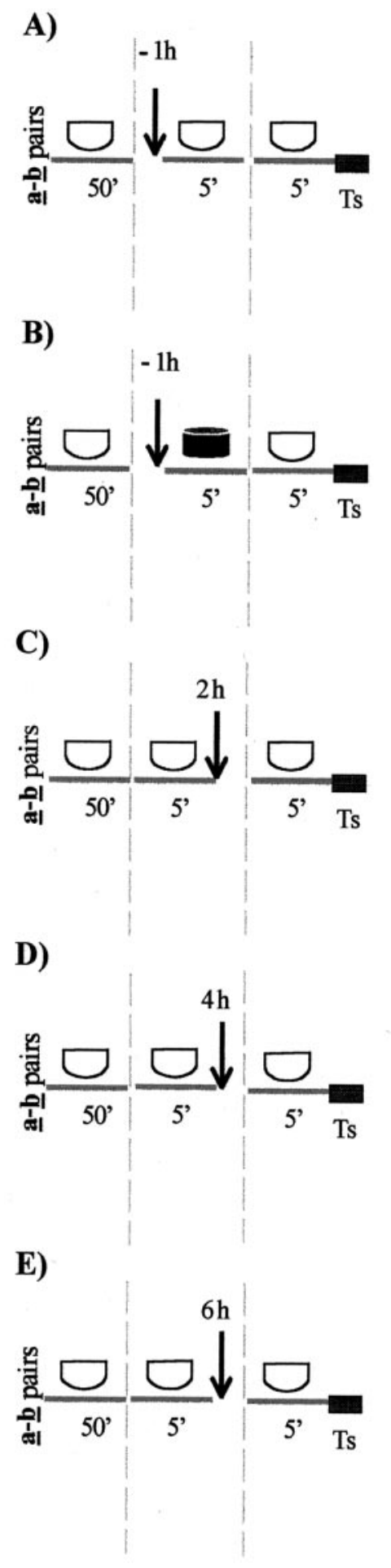

\section{Test performance}
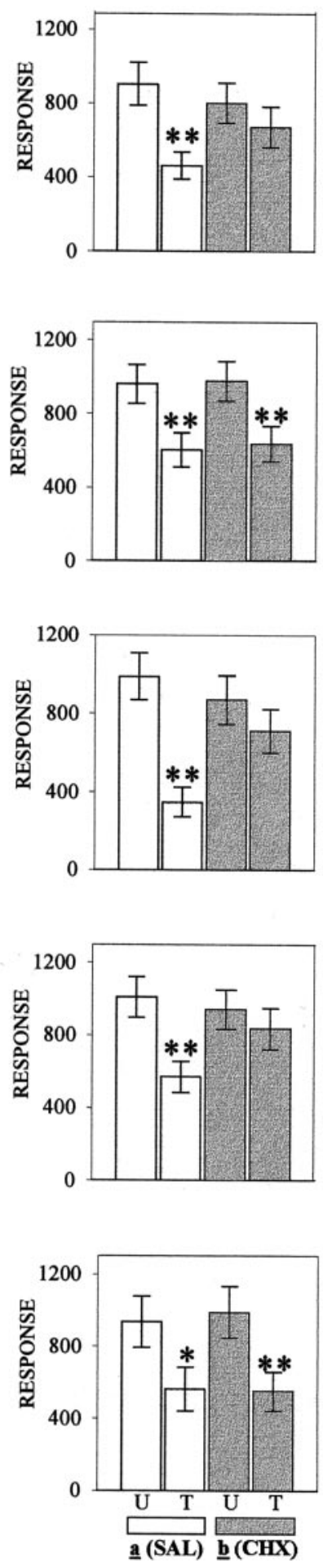

Figure 1. Effect of $\mathrm{CHX}$ administered at diverse times relative to reexposure to the original learning context. Left, Behavioral protocols. Icons stand for the crabs that remained in a container during the time interval indicated below the icon; white icon, standard context; black icon, different context. Arrow, An injection of $50 \mu \mathrm{l}$ of physiological solution (SAL) or an injection of $50 \mu \mathrm{l}$ of CHX (15 $\mu \mathrm{g}$ per crab). Day 1, Training session in the standard context for $50 \mathrm{~min}$; U-T pair $a$ or $b$ in each

$b$ (CHX-injected). Figure $1 A$ presents test results (day 3 ) corresponding to groups injected on day 2 at $1 \mathrm{hr}$ before the $5 \mathrm{~min}$ re-exposure to the standard context. Planned comparisons $\left(\right.$ ANOVA; $\left.F_{(3,144)}=3.35 ; p<0.02\right)($ right bar chart) showed a significant difference (memory retention) for the SAL-injected group $a(p<0.003)$ but no significant difference (memory impairment) for the $\mathrm{CHX}$-injected group $b(p=0.34)$. In contrast, when groups were exposed to the different context (Fig. 1B), planned comparisons (ANOVA; $F_{(3,136)}=3.93 ; p<0.0097$ ) presented significant differences for both pairs of groups $(p<$ 0.01); i.e., CHX failed to disrupt memory. The succeeding three experiments explored the effect of injections given at diverse time intervals after $5 \mathrm{~min}$ of re-exposure to the standard context on day 2. With respect to groups injected $2 \mathrm{hr}$ later (Fig. $1 C$ ), planned comparisons (ANOVA; $F_{(3,156)}=6.65 ; p<0.003$ ) revealed a significant difference for the SAL-injected pair $a(p<0.0001)$ but not for the CHX-injected pair $b(p=0.75)$. A similar pattern of test results was found with groups injected $4 \mathrm{hr}$ after reexposure to the standard context on day 2 (Fig. 1D), because planned comparisons (ANOVA; $\left.F_{(3,140)}=2.91 ; p<0.036\right)$ disclosed a significant difference for pair $a(p<0.0001)$ but not for pair $b(p=0.47)$. However, when the interval between the 5 -min re-exposure and injection was delayed to $6 \mathrm{hr}$ (Fig. $1 E$ ), the $\mathrm{CHX}$ injection no longer impaired CSM. In fact, planned comparisons $\left(\right.$ ANOVA; $\left.F_{(3,152)}=3.30 ; p<0.023\right)$ showed significant differences for both the SAL- and CHX-injected pair of groups $(p<$ 0.04 and $p<0.01$, respectively). Thus, the CSM acquired on day 1 and reactivated by $5 \mathrm{~min}$ of re-exposure to the training context on day 2 was blocked by CHX injection administered $1 \mathrm{hr}$ before or either 2 or $4 \mathrm{hr}$ after but not $6 \mathrm{hr}$ after reactivation. These results may be considered the first suggestion in this article that stable and consolidated memory could again become active and labile (reactivated) by brief re-exposure to the original learning context.

Two additional experiments, including one U-T pair of SALinjected groups and another of $\mathrm{CHX}$-injected groups, were performed. The first experiment (Fig. 2) was aimed at determining whether the amnesic effect of $\mathrm{CHX}$ could be observed immediately after 5 min of crab re-exposure to the standard context. For this purpose, both U-T pairs were injected $1 \mathrm{hr}$ before reexposure, but unlike other experiments of this series, were tested immediately after re-exposure. No memory-disrupting effect was found in either pair of groups. Planned comparisons (ANOVA; $\left.F_{(3,144)}=9.6 ; p<0.001\right)$ revealed significant differences for both pair $a$ and pair $b(p<0.0001$ and $p<0.028$, respectively). The second experiment (Fig. 3) was performed to explore to what extent CSM reactivation could be affected by doubling the time

$\leftarrow$

experiment has a trained group $(T)$ with 15 trials separated by 3 min and an untrained group $(U)$ without training. Day 2, Treatment session, in which U-T pair $a$ of each experiment is injected with SAL and U-T pair $b$ is injected with CHX; injections indicated by an arrow were given $1 \mathrm{hr}$ $(-1 h)$ before re-exposure to the standard context $(A)$ or $1 \mathrm{hr}(-1 h)$ before exposure to the different context $(B)$; alternatively, injections indicated by an arrow were given at $2 \mathrm{hr}(2 h)$ after re-exposure $(C), 4 \mathrm{hr}$ $(4 h)$ after re-exposure $(D)$, or $6 \mathrm{hr}(6 h)$ after re-exposure $(E)$. Day 3 , Testing session; all groups stay for $5 \mathrm{~min}$ in the standard context followed by test trial $(T s)$. Right, Test trial on day 3. Ordinate, Response (i.e., average of the escape response scores for the test trial \pm SEM). Open bars, Groups of U-T pair $a$ (SAL-injected); gray bars, groups of U-T pair $b$ (CHX-injected). Planned comparisons: $* p<0.05$, significant $\mathrm{T}<\mathrm{U}$ difference; ${ }^{* *} p<0.01$, significant $\mathrm{T}<\mathrm{U}$ difference (both memory retention). 


\section{Day 1 Day 2}

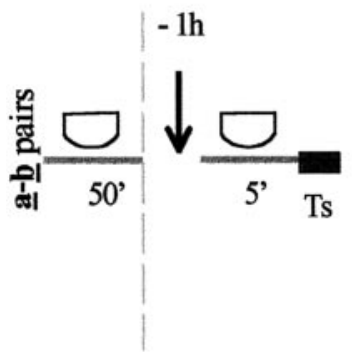

Test performance

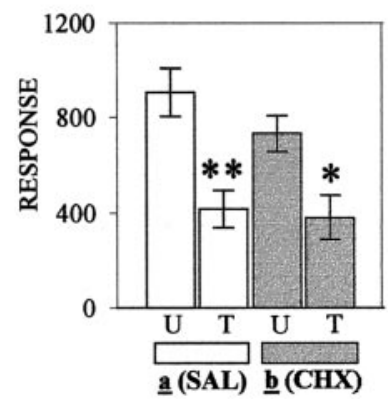

Figure 2. Effect of $\mathrm{CHX}$ administered $1 \mathrm{hr}(-1 h)$ before re-exposure to the original learning context and the test trial given immediately after re-exposure. All symbols and the protocol are as described in Figure $1 A$, except the test trial (TS) given immediately after re-exposure on day 2. Right, Test trial on day 2. Symbols are as described in Figure 1A. Asterisks are as in Figure 1.

\section{Day 1 Day 3 Day 4}
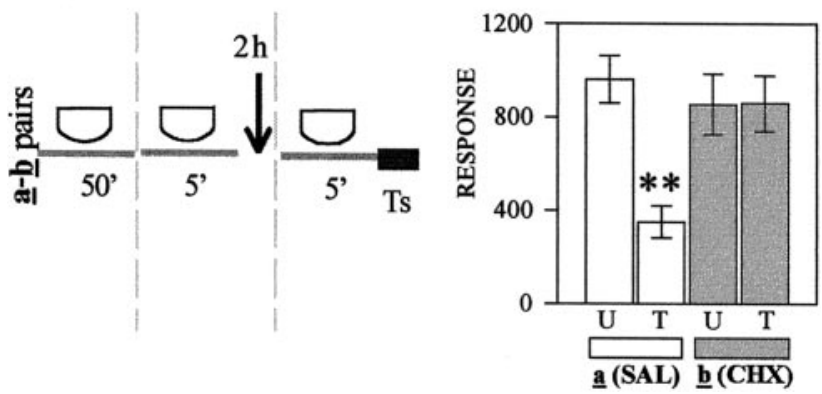

Figure 3. Effect of $\mathrm{CHX}$ administered $2 \mathrm{hr}(2 h)$ after re-exposure to the original learning context during day 3 and tested on day 4. Left, Behavioral protocols. All symbols and the protocol are as described in Figure $1 C$, except the treatment session given on day 3 and the test session on day 4. Ts, Test trial. Right, Test trial on day 3. Symbols are as described in Figure 1C. Asterisks are as in Figure 1.

interval between training and contextual re-exposure. For this purpose, the protocol was the same as that used in the experiment shown in Figure $1 C$, but with the 5 min context re-exposure shifted to $48 \mathrm{hr}$ after training (day 3 ), so that the test trial was performed on day 4. Planned comparisons on these data (ANOVA; $\left.F_{(3,156)}=6.59 ; p<0.003\right)$ showed differences similar to those of Figure $1 C$ [i.e., memory retention $(\mathrm{T}<\mathrm{U})$ for the SAL-injected group $(p<0.001)$ but memory impairment for the CHX-injected pair $(p=0.99)]$.

\section{Effect of NMDAR antagonist MK-801 administered at diverse times to re-exposure to the original learning context}

The impairing effect of the vertebrate NMDAR antagonist MK801 on newly acquired CSM was assessed at diverse time intervals relative to training (Troncoso and Maldonado, 2002). Here, we explored whether a similar dose of MK-801 $(1 \mu \mathrm{g} / \mathrm{gm})$ acts on retrieved CSM.

In the four experiments presented in Figure 4A-D (left panels), crabs were injected with either SAL or MK-801 at varying times relative to the $5 \mathrm{~min}$ of context exposure (day 2) and tested on day

\section{Day 1 Day 2 Day 3}

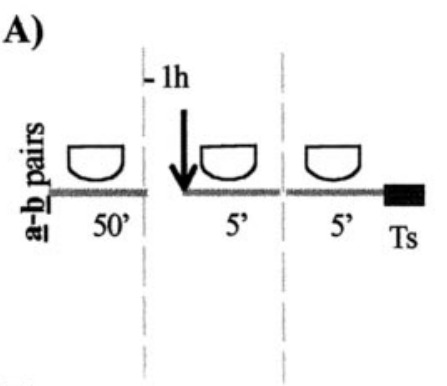

Test performance
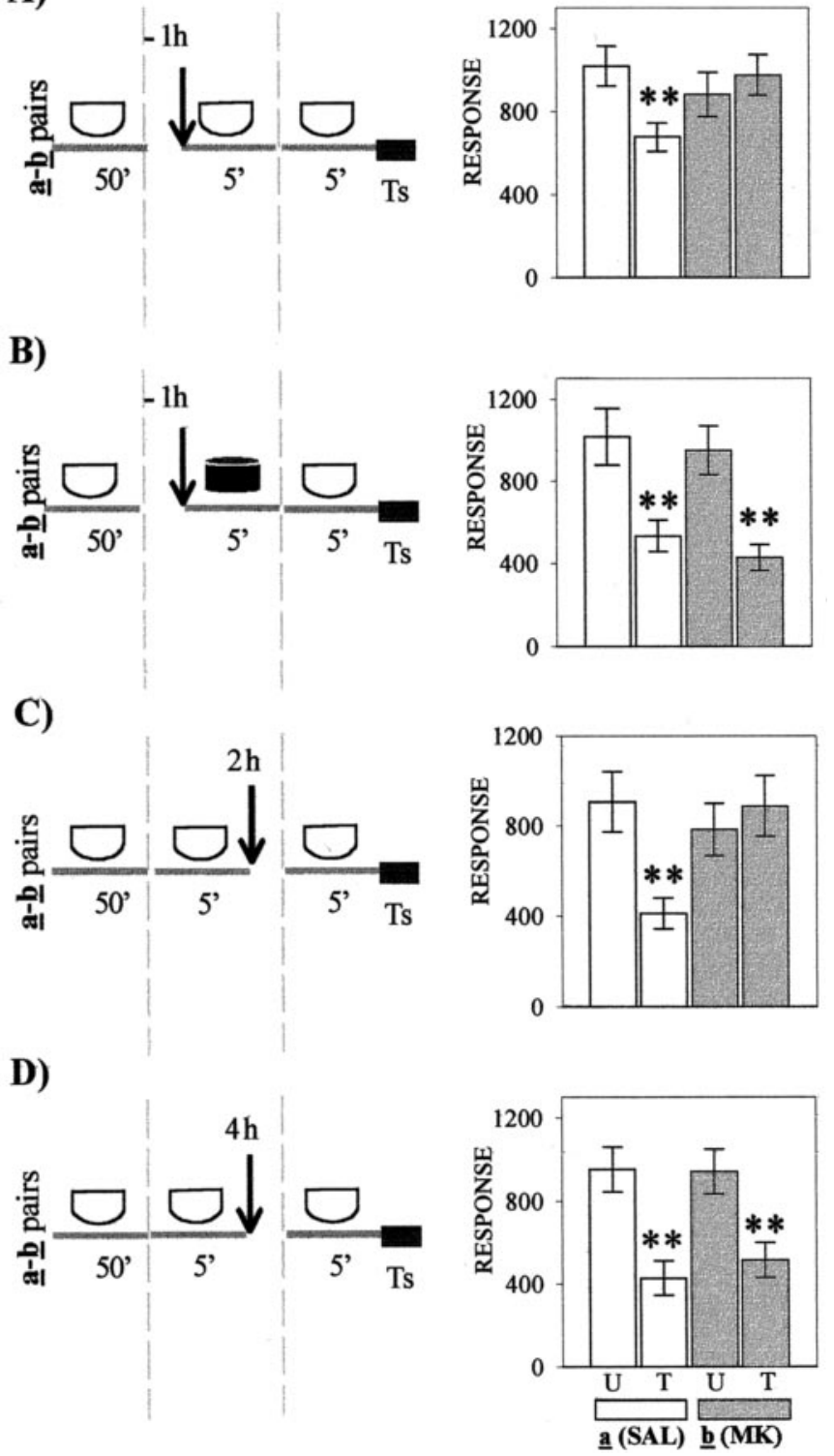

Figure 4. Effect of the NMDA receptor antagonist MK-801 administered at diverse times relative to re-exposure to the original learning context. Left, Behavioral protocols. All symbols and protocols are as described in Figure $1 A-D$, except on day 2, when U-T pair $a$ of each experiment is injected with SAL and U-T pair $b$ is injected with MK-801 $(M K) . T s$, Test trial. Right, Test trial on day 3. Symbols are as described in Figure 1. Asterisks are as in Figure 1.

3. Each U-T pair $a$ was SAL-injected, whereas each U-T pair $b$ was MK-801-injected. Figure $4 A$ presents test trial results (day 3 ) corresponding to groups injected $1 \mathrm{hr}$ before $5 \mathrm{~min}$ of re-exposure to the standard context. Memory retention for the SAL-injected pair $a(p<0.009)$ and memory impairment for MK-801-injected pair $b(p=0.46)$ were shown by planned comparisons (ANOVA; $\left.F_{(3,156)}=2.6 ; p<0.04\right)$. In contrast, when the 5 min exposure was to the different context (Fig. 4B), planned comparisons $\left(\right.$ ANOVA; $\left.F_{(3,116)}=8.08 ; p<0.0005\right)$ disclosed significant differences for both pairs of groups $(p<0.001$ for pair $a$ and $p<$ 


\section{Day 1 Day 2}

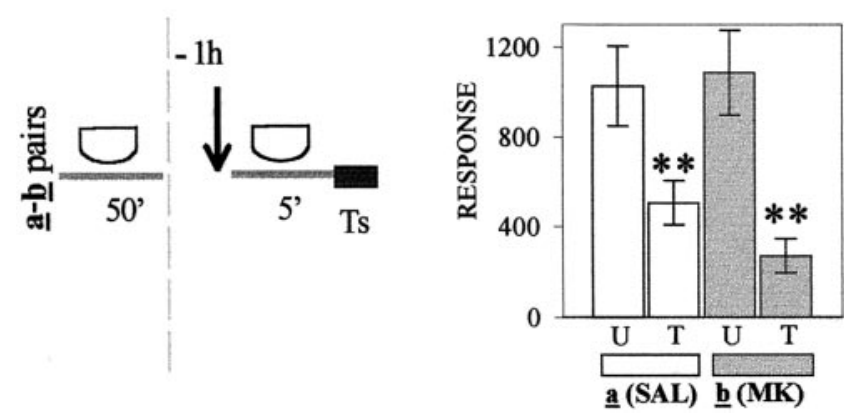

Figure 5. Effect of the NMDA receptor antagonist MK-801 (MK) administered $1 \mathrm{hr}$ before re-exposure to the original context and the test trial given immediately after re-exposure. Left, Behavioral protocols. All symbols and the protocol are as described in Figure $4 A$, except for the test trial $(T s)$ given immediately after re-exposure on day 2 . Right, Test trial on day 3. Symbols are as described in Figure 1 A. Asterisks are as in Figure 1.

0.0004 for pair $b$ ); i.e., MK-801 failed to disrupt memory when a context different from that used at training was presented during the $5 \mathrm{~min}$ exposure on day 2 . With respect to groups injected $2 \mathrm{hr}$ after 5 min of re-exposure to the standard context (Fig. 4C), planned comparisons performed on test scores (ANOVA; $\left.F_{(3,156)}=3.9 ; p<0.009\right)$ disclosed significant differences for the SAL-injected pair $(p<0.003)$ but not for the MK-801injected pair $(p=0.6)$. However, when the interval time between contextual re-exposure and injection was delayed to $4 \mathrm{hr}$ (Fig. $4 D)$, the MK-801 injection no longer impaired CSM. In fact, planned comparisons (ANOVA; $F_{(3,156)}=8.23 ; p<0.0001$ ) showed significant differences for both pair $a$ and pair $b(p<$ 0.001 and $p<0.002$, respectively).

Finally, one experiment was performed to analyze the effect of MK-801 on CSM when administered $1 \mathrm{hr}$ before the $5 \mathrm{~min}$ context re-exposure and tested immediately after re-exposure on the same day 2. The design included two U-T pairs of groups, namely one SAL-injected pair $a$ and one MK-801-injected pair $b$. Results are illustrated in Figure 5. No memory-disrupting effect was found in either pair of groups. Planned comparisons $\left(\right.$ ANOVA; $\left.F_{(3,116)}=6.98 ; p<0.0002\right)$ revealed significant differences for both pair $a$ and pair $b(p<0.01$ and 0.0002, respectively).

Thus, the CSM acquired on day 1 and tested on day 3 was impaired by MK-801 administered $1 \mathrm{hr}$ before or $2 \mathrm{hr}$ after, but not $4 \mathrm{hr}$ after, re-exposure on day 2. Conversely, memory seems to be intact if MK-801 is administered $1 \mathrm{hr}$ before context re-exposure and tested immediately after re-exposure on the same day 2 .

\section{DISCUSSION}

These experiments provide clear evidence that the robust CSM acquired by the crab through spaced training (Pedreira et al., 1995; Romano et al., 1996a,b; Freudenthal et al., 1998; Locatelli et al., 2000, 2002) again becomes labile after $5 \mathrm{~min}$ of re-exposure to the learning context, proving vulnerable to $\mathrm{CHX}$ or $\mathrm{MK}-801$ injection. Results are interpreted according to the view, stemming from findings obtained in vertebrates (Nader et al., 2000), that memory retrieved by a reminder passes from a dormant and stable stage to an active and labile one (reactivation), which undergoes a time-dependent consolidation process (reconsolidation) (Przybyslawski and Sara, 1997; Przybyslawski et al., 1999; Sara, 2000). The effect of the two amnesic agents cannot be accounted for in terms other than CSM impairment. First, no significant difference between untrained groups of a same experiment could be found throughout. Therefore, when no difference is disclosed for a U-T pair treated by CHX or MK-801, such result could hardly be attributable to a depressing or enhancing effect of the amnesic agent on test performance. Second, either CHX or MK-801 failed to produce amnesia whenever a context different from that of learning was used as reminder, indicating that faithfulness to the original context is a necessary condition for the amnesic agent to induce amnesia. Third, a temporal gradient of effectiveness was demonstrated for either $\mathrm{CHX}$ or MK-801, a fact that is incompatible with an explanation of results in terms of proactive effects on test performance.

Amnesia for CSM may be explained by reactivation hindrance, caused by interference with reactivation mechanisms, straightforwardly by a change in the original learning context because drug injection incorporates new internal cues, or by interference with the reconsolidation process. However, the explanation in terms of reactivation blockade should be ruled out, because retention of the old memory is not affected when reactivation is hindered (Figs. 1B, 4B).

Administration of $15 \mu \mathrm{g}$ of $\mathrm{CHX}$ per crab (CHX injection) produces disruption of the context-reactivated memory within a time window estimated between $1 \mathrm{hr}$ before and $4 \mathrm{hr}$ after reactivation. The time window for the $\mathrm{CHX}$ amnesic effect seems to be similar for both consolidation and reconsolidation (Pedreira et al., 1995; Hermitte et al., 1999). The finding that $\mathrm{CHX}$ has no effect when tested immediately after contextual re-exposure suggests that such amnesia is most likely attributable to interference with the molecular mechanisms mediating reconsolidation but not to nonspecific dysfunctional effects. Conversely, the fact that CHX maintains its amnesic effect despite the doubling of the time interval between training and contextual re-exposure is consistent with results obtained in rats (Nader et al., 2000).

Apart from our present results with the crab, two other studies, both with rats, have also reported that administration of a protein synthesis inhibitor given after memory reactivation causes amnesia for the original learning (Judge and Quartermain, 1982; Nader et al., 2000). Hence, the need to synthesize new proteins for reconsolidation would be a tenet valid for most animal species, namely, a principle as universal as the need of new proteins for consolidation (Alberini, 1999).

The effect of the NMDAR antagonist MK-801 on reconsolidation was explored, because this drug $(1 \mu \mathrm{g} / \mathrm{gm})$ had been shown to induce amnesia for CSM when injected immediately before training or up to $4 \mathrm{hr}$ after training (Troncoso and Maldonado, 2002). The present results revealed that the same dose of MK-801 produces disruption of the CSM within a time window ranging from $1 \mathrm{hr}$ before up to $2 \mathrm{hr}$ after reactivation, but no effect when tested immediately after contextual re-exposure. Some previous experiments with vertebrates have also shown that reactivation of a well established memory triggers cellular events depending on NMDA receptors (Summers et al., 1997; Przybyslawski et al., 1999), but other reports have indicated that the NMDA receptor does not appear to be involved in memory retrieval (Steele and Morris, 1999; Shimizu et al., 2000).

According to an interpretive model of CSM retrieval (Tomsic et al., 1998; Hermitte et al., 1999; Maldonado, 2002), re-exposure 
of a trained crab to the learning context evokes a CSM representation that induces a freezing response as soon as the animal is faced with the VDS. No previous evidence has shown that such memory representation is already present before VDS display; however, results of this study support the proposal. Mere reexposure to the original learning context, even in the absence of VDS presentation, is quite enough for an amnesic agent to impair reactivated memory. Thus, these findings also support the associative nature of CSM and, specifically, the existence of an associative link between signal and context as the basis of this memory process.

Given the parallelism between results with crabs and those with vertebrates concerning certain features of the reactivated memory, the probable adaptive value of such properties should be explored, in particular, that of reconsolidation and subsequent relabilization; specifically, what would be the adaptive value of reconsolidation and therefore of memory relabilization that necessarily follows after reactivation. Several speculative arguments have been advanced with regard to experiments with vertebrates to account for the functionality of such a memory phase. Reconsolidation was proposed as a process of reorganization of past experience within the current cognitive context (Spear and Mueller, 1984; Sara, 1985), during which new information is integrated on the past background and some forgettable context attributes are strengthened (Sara, 2000).

This article offers results in keeping with two main tenets of the reactivation/reconsolidation hypothesis: first, reactivation converts memory from a dormant-stable state to an active-labile one; and second, the postacquisition cascade of intracellular events is to some extent recapitulated whenever memory is reactivated. Both tenets were grounded on experiments with vertebrates (Nader et al., 2000; Sara, 2000); therefore, the present findings with a crustacean suggest the persistence through evolution of molecular mechanisms subserving both consolidation and reconsolidation phases of memory. The shared mechanisms would be the basic tools used by evolution to promote adaptive changes through phylogenetically disparate animals (Carew, 2000).

\section{REFERENCES}

Abel T, Kandel ER (1998) Positive and negative regulatory mechanisms that mediated long-term memory storage. Brain Res Brain Res Rev 26:360-378.

Alberini MC (1999) Genes to remember. J Exp Biol 202:2887-2891.

Applewhite BP, Gardner FT, Lapan E (1969) Physiology of habituation learning in a protozoan. Trans NY Acad Sci 31:842-849.

Berón de Astrada M, Maldonado H (1999) Two related forms of longterm habituation in the crab Chasmagnathus are differentially affected by scopolamine. Pharmacol Biochem Behav 63:109-118.

Carew TJ (2000) Behavioral neurobiology: the cellular organization of natural behavior. Sunderland, MA: Sinauer.

Delorenzi A, Pedreira ME, Romano A, García SI, Pirola CJ, Nahmod VE, Maldonado H (1996) Acute administration of angiotensin II enhances long-term memory in the crab Chasmagnathus. Brain Res Bull 41:211-220.

Delorenzi A, Dimant B, Frenkel L, Nahmod V, Nassel D, Maldonado H (2000) High environmental salinity induces memory enhancement and increases brain angiotensin-like peptides in the crab Chasmagnathus. J Exp Biol 203:3369-3379.

Freudenthal R, Romano A (2000) Participation of Rel/NF $\kappa$ B transcription factors in long-term memory in the crab Chasmagnathus. Brain Res 885:274-281.

Freudenthal R, Locatelli F, Hermitte G, Maldonado H, Delorenzi A, Romano A (1998) $\kappa$ B-like DNA binding activity is enhanced after spaced training that induces long-term memory in the crab Chasmagnathus. Neurosci Lett 242:143-146.

Hermitte G, Pedreira ME, Tomsic D, Maldonado H (1999) Context shift and protein synthesis inhibition disrupt long-term habituation after spaced, but not massed, training in the crab Chasmagnathus. Neurobiol Learn Mem 71:34-49.
Hoeger R, Florey E (1989) Catecholamine degradation in the hemolymph of the Chinese crab, Eriocheir sinesis. Comp Biochem Physiol 92C:323-327.

Howell DC (1987) Statistical methods for psychology. Boston: Duxbury. Judge ME, Quartermain D (1982) Alleviation of anisomycin-induced amnesia by pre-test treatment with lysine-vasopressin. Pharmacol Biochem Behav 16:463-466.

Locatelli F, Lafourcade C, Maldonado H, Romano A (2000) Characterization of cAMP-dependent protein kinase isoforms in the brain of the crab Chasmagnathus. J Comp Physiol [B] 171:33-40.

Locatelli F, Maldonado H, Romano A (2002) Two critical periods for cAMP dependent protein kinase activity during long-term memory consolidation in the crab Chasmagnathus. Neurobiol Learn Mem 77:234-349.

Lozada M, Romano A, Maldonado H (1990) Long-term habituation to a danger stimulus in the crab Chasmagnathus granulatus. Physiol Behav 47:35-41.

Maldonado H (2002) Crustacean as model to investigate memory illustrated by extensive behavioral and physiological studies in Chasmagnathus. In: The crustacean nervous system (Wiese K, ed), pp 314-327. Springer: Berlin.

Menzel R (2001) Searching for the memory trace in a mini-brain, the honeybee. Learn Mem 8:53-62.

Merlo E, Freudenthal R, Romano A (2002) The I $\kappa$ B kinase inhibitor sulfasalazine impairs long-term memory in the crab Chasmagnathus. Neuroscience 112:161-172.

Misanin JR, Miller RR, Lewis DJ (1968) Retrograde amnesia produced by electroconvulsive shock following reactivation of a consolidated memory trace. Science 160:554-555.

Müller U (2000) Prolonged activation of cAMP-dependent protein kinase during conditioning induces long-term memory in honeybees. Neuron 27:159-168.

Nadel L, Land C (2000) Memory traces revisited. Nat Rev Neurosci 1:209-212.

Nader K, Schafe GE, Le Doux JE (2000) Fear memories require protein synthesis in the amygdala for reconsolidation after retrieval. Nature 406:722-726.

Pedreira ME, Dimant B, Tomsic D, Quesada-Allue LA, Maldonado H (1995) Cycloheximide inhibits context memory and long-term habituation in the crab Chasmagnathus. Pharmacol Biochem Behav 52:385-395.

Pedreira ME, Dimant B, Maldonado H (1996) Inhibitors of protein and RNA synthesis block context memory and long-term habituation in the crab Chasmagnathus. Pharmacol Biochem Behav 54:611-617.

Peeke HVS, Veno A (1976) Stimulus specificity of habituated aggression in the three-spined sticklebacks Gasterosteus acualeatus. Z Tierpsychol 40:53-58.

Pereyra P, Saraco M, Maldonado H (1999) Decreased response or alternative defensive strategy in escape: two different types of longterm memory in the crab Chasmagnathus. J Comp Physiol 184: 301-310.

Pereyra P, Gonzalez Portino E, Maldonado H (2000) Conditioned defensive freezing in the crab is context-specific but not triggered by the context. Neurobiol Learn Mem 74:119-134.

Przybyslawski J, Sara SJ (1997) Reconsolidation of memory after its reactivation. Behav Brain Res 84:241-246.

Przybyslawski J, Roulet P, Sara SJ (1999) Attenuation of emotional and nonemotional memories after their reactivation: role of $\beta$-adrenergic receptors. J Neurosci 19:6623-6628.

Rescorla DA (1988) Behavioral studies of pavlovian conditioning. Annu Rev Neurosci 1:320-352.

Romano A, Delorenzi A, Pedreira ME, Tomsic D, Maldonado $\mathrm{H}$ (1996a) Acute administration of a permeant analog of cAMP and phosphodiesterase inhibitor improve long-term habituation in the crab Chasmagnathus. Behav Brain Res 75:119-125.

Romano A, Locatelli F, Delorenzi A, Pedreira ME, Maldonado $\mathrm{H}$ (1996b) Effects of activation and inhibition of cAMP-dependent protein kinase on long-term habituation in the crab Chasmagnathus. Brain Res 735:131-140.

Rosenthal R, Rosnow RL (1985) Contrast analysis focused comparisons in the analysis of variance. Cambridge, UK: Cambridge UP.

Sara SJ (1985) Noradrenergic modulation of selective attention: its role in memory retrieval. Ann NY Acad Sci 444:178-193.

Sara SJ (2000) Retrieval and reconsolidation: toward a neurobiology of remembering. Learn Mem 7:73-84.

Sekiguchi T, Yamada A, Suzuki H (1997) Reactivation-dependent changes in memory states in the terrestrial slug Limax flavus. Learn Mem 4:356-364.

Shimizu E, Tang YP, Rampon C, Tsien JZ (2000) NMDA receptordependent synaptic reinforcement as a crucial process for memory consolidation. Science 290:1170-1174. 
Spear NE, Mueller CW (1984) Consolidation as a function of retrieval. In: Memory consolidation: psychobiology of cognition (Weingartner $\mathrm{H}$, Parker ES, eds). Hillsdale, NJ: Erlbaum.

Steele RJ, Morris RGM (1999) Delay-dependent impairment of a matching to place task with chronic intrahippocampal infusion of the NMDA antagonist D-AP5. Hippocampus 9:118-136.

Summers MJ, Crowe SF, Ng KT (1997) Administration of DL-2-amino5-phosphonovaleric acid (AP5) induces transient inhibition of reminder-activated memory retrieval in day-old chicks. Brain Res Cogn Brain Res 5:311-321.

Tomsic D, Maldonado H, Rakitin A (1991) Morphine and GABA: effects on perception, escape response and long-term habituation to a danger stimulus in the crab Chasmagnathus. Brain Res Bull 26:694-706.

Tomsic D, Pedreira ME, Romano A, Hermitte G, Maldonado H (1998) Context-US association as a determinant of long-term habituation in the crab Chasmagnathus. Anim Learn Behav 26:196-204.

Troncoso J, Maldonado H (2002) Two related forms of memory in the crab Chasmagnathus are differentially affected by NMDA receptor antagonists. Pharmacol Biochem Behav 72:251-265.

Tully T (1998) Toward a molecular biology of memory: the light's coming on! Nat Neurosci 1:543-545.

Tully T, Preat T, Boynton SC, Del Vecchio M (1994) Genetic dissection of consolidated memory in Drosophila. Cell 79:35-47. 